\title{
Mesangial Cells Exhibit Features of Antigen-Presenting Cells and Activate CD4+ T Cell Responses
}

\author{
Hongyu Yu, ${ }^{1,2}$ Shaoyuan Cui, ${ }^{2}$ Yan $\mathrm{Mei}^{2}$ Qinggang $\mathrm{Li}^{2}{ }^{2}$ Lingling $\mathrm{Wu}^{2}$ Shuwei Duan, \\ Guangyan Cai $\mathbb{D},{ }^{2}$ Hanyu Zhu, ${ }^{2}$ Bo Fu, ${ }^{2}$ Li Zhang, ${ }^{2}$ Zhe Feng $\mathbb{D},{ }^{2}$ and Xiangmei Chen $\mathbb{D}^{1,2}$ \\ ${ }^{1}$ Department of Nephrology, The Second Hospital of Jilin University, Changchun, Jilin, China \\ ${ }^{2}$ Department of Nephrology, Chinese PLA General Hospital, Chinese PLA Institute of Nephrology, State Key Laboratory of \\ Kidney Diseases, National Clinical Research Center for Kidney Diseases, Beijing, China
}

Correspondence should be addressed to Zhe Feng; zhezhe_4025@126.com and Xiangmei Chen; xmchen301@126.com

Received 6 September 2018; Revised 1 April 2019; Accepted 14 May 2019; Published 17 June 2019

Academic Editor: Alexandre Keller

Copyright (c) 2019 Hongyu Yu et al. This is an open access article distributed under the Creative Commons Attribution License, which permits unrestricted use, distribution, and reproduction in any medium, provided the original work is properly cited.

\begin{abstract}
Background. Mesangial cells play a prominent role in the development of inflammatory diseases and autoimmune disorders of the kidney. Mesangial cells perform the essential functions of helping to ensure that the glomerular structure is stable and regulating capillary flow, and activated mesangial cells acquire proinflammatory activities. We investigated whether activated mesangial cells display immune properties and control the development of $\mathrm{T}$ cell immunity. Methods. Flow cytometry analysis was used to study the expression of antigen-presenting cell surface markers and costimulatory molecules in mesangial cells. CD4+ T cell activation induced by mesangial cells was detected in terms of T cell proliferation and cytokine production. Results. IFN- $\gamma$ treated mesangial cells express membrane proteins involved in antigen presentation and $\mathrm{T}$ cell activation, including MHC-II, ICAM-1, CD40, and CD80. This finding suggests that activated mesangial cells can take up and present antigenic peptides to initiate CD4+ T cell responses and thus act as nonprofessional antigen-presenting cells. Polarization of naïve CD4+ T cells (Th0 cells) towards the Th1 phenotype was induced by coculture with activated mesangial cells, and the resulting Th1 cells showed increased mRNA and protein expression of inflammation-associated genes. Conclusion. Mesangial cells can present antigen and modulate CD4+ T lymphocyte proliferation and differentiation. Interactions between mesangial cells and $\mathrm{T}$ cells are essential for sustaining the inflammatory response in a variety of glomerulonephritides. Therefore, mesangial cells might participate in immune function in the kidney.
\end{abstract}

\section{Introduction}

Mesangial cell-mediated glomerulonephritis (GN) is a frequent cause of end-stage renal disease (ESRD) [1,2]. Mesangial cell injury is involved in the pathogenesis of $\operatorname{IgA}$ nephropathy (IgAN), diabetic nephropathy (DN), and lupus nephritis (LN) and plays an important role in the progression of kidney disease. The functions of mesangial cells include the formation of capillary loops during development, interactions with other renal cells, contractions to regulate capillary flow, and the removal of macromolecules. In addition to these actions, mesangial cells also play a role in promoting kidney inflammation [3]. Activated mesangial cells accumulate in injured mesangial areas, where they express cell adhesion molecules and secrete various proinflammatory cytokines [4-6].

Inflammatory cells are involved in the development of kidney disease $[7,8]$, but the local immunity in a diseased kidney is not completely understood. In some kidney diseases, a number of antigens are processed by antigenpresenting cells (APCs), such as dendritic cells (DCs) and $\mathrm{B}$ lymphocytes, and presented to $\mathrm{T}$ lymphocytes, which become activated and accumulate, leading to progressive inflammation of the kidney [9]. However, CD103+ kidney DCs can protect against progressive GN by maintaining IL10-producing T regulatory (Treg) cells [10]. Therefore, APCs can play an important role in the resolution or progression of renal disease. Activated mesangial cells express molecules 
required for antigen presentation, such as major histocompatibility complex (MHC) class II, and might participate in local inflammatory responses by meeting the accessory cell requirement for the interaction with $\mathrm{CD} 4+\mathrm{T}$ cells [11]. An animal model showed that activated CD4+ $\mathrm{T}$ cells target mesangial antigens and initiate GN [12, 13]. However, it is unclear whether these antigen-presenting features of mesangial cells impact CD4+ T cells.

We hypothesized that activated mesangial cells play a role in renal immune function, and in this study, we demonstrated that mesangial cells act as nonprofessional APCs to activate $\mathrm{CD} 4+\mathrm{T}$ cells.

\section{Materials and Methods}

2.1. Cell Culture. Human primary mesangial cells (HMCs, ScienCell Research Laboratories Inc., Basel, Switzerland) were cultured in Mesangial Cell Medium (ScienCell Research Laboratories Inc.). Mouse mesangial cells (MMCs; ATCC, Manassas, VA, USA) were derived from glomerular explants of SV40 transgenic mice on the C57BL/6 background [14] and were cultured in Dulbecco's modified Eagle's medium/Ham's F12 medium (3:1 mixture) (ATCC) with 5\% fetal bovine serum (FBS) (HyClone Laboratories Inc., South Logan, UT, USA). JAWSII immature mouse DCs (originating from the C57BL/6 mouse strain) (ATCC) were cultured in Alpha Minimum Essential Medium with 20\% FBS and $5 \mathrm{ng} / \mathrm{ml}$ murine GM-CSF (PeproTech, Rocky Hill, NJ, USA) [15]. All the cells were grown in a humidified atmosphere $\left(5 \% \mathrm{CO}_{2}\right)$ at $37^{\circ} \mathrm{C}$. The HMCs were stimulated with $50 \mathrm{ng} / \mathrm{ml}$ human IFN- $\gamma$ (Sigma-Aldrich, St. Louis, MO, USA) for $48 \mathrm{~h}$ [16]. The MMCs were stimulated with $50 \mathrm{ng} / \mathrm{ml}$ recombinant mouse IFN- $\gamma$ (Sigma-Aldrich) for $48 \mathrm{~h}$, and the JAWSII cells were stimulated with $2 \mu \mathrm{g} / \mathrm{ml}$ lipopolysaccharide (LPS) (from Escherichia coli O111:B4, Sigma-Aldrich) for $48 \mathrm{~h}$.

2.2. Isolation of Nä̈ve CD4+ T Cells. Human naïve T cells, defined as CD4+ and CD45RA+ cells, were isolated from human peripheral blood mononuclear cells (PBMCs) through negative selection using a Naïve CD4+ T Cell Isolation Kit II (human) following the manufacturer's instructions. Briefly, naïve CD4+ T cells were negatively isolated with Naïve CD4+ T Cell Biotin-Antibody Cocktail II (biotin-conjugated monoclonal antibodies against CD8, CD14, CD15, CD16, CD19, CD25, CD34, CD36, CD45RO, CD56, CD123, TCR $\gamma / \delta$, HLA-DR, and CD235a (Glycophorin A)) and Naïve CD4+ T Cell MicroBead Cocktail II using an LD column (Miltenyi Biotec) in the magnetic field of a suitable MACS separator. The flow-through containing unlabelled cells, which represented the enriched naïve CD4+ T cells, was collected (Figure S1(a)). Murine naïve CD4+ T cells, defined as CD45+, CD3E+, CD4+, and CD62L+ cells, were isolated from the spleens of OT-II transgenic C57BL/6 mice (Jackson Laboratory, Bar Harbour, ME, USA) by negative selection using a Naïve CD4+ T Cell Isolation Kit (mouse) (Miltenyi Biotec, Auburn, CA) [17]. Briefly, naïve CD4+ T cells were negatively isolated with Biotin-Antibody Cocktail (biotin-conjugated monoclonal antibodies against CD8a, CD11b, CD11c, CD19, CD25, CD45R (B220), CD49b
(DX5), CD105, MHC class II, Ter-119, and TCR $\gamma / \delta$ ), antibiotin MicroBeads, and CD44 MicroBeads using an LD column (Miltenyi Biotec) in the magnetic field of a suitable MACS separator. The flow-through containing unlabelled cells, which represented the enriched naïve CD4+ T cells, was collected (Figure S1(b)).

2.3. Coculture of Activated HMCs with Nä̈ve CD4+ T Lymphocytes. Human PBMCs were isolated from normal volunteers. HMCs were stimulated with IFN- $\gamma$ for $48 \mathrm{~h}$, washed twice with PBS, trypsinized, and irradiated with 6,000 rads, which is a dose that has been shown to stop proliferation without affecting cell viability or membrane protein expression. Subsequently, the IFN- $\gamma$-treated HMCs were cocultured with freshly isolated naïve CD4+ T cells in RPMI 1640 (Gibco, Paisley, UK) with 10\% FBS for $48 \mathrm{~h}$. All of the procedures met the ethical guidelines, and the protocol was approved by the Hospital Research Ethics Committee.

2.4. Differentiation of Th1 Cells Cocultured with HMCs. One day before, a culture dish coated with anti-CD $3 \varepsilon$ antibodies $(2 \mu \mathrm{g} / \mathrm{ml}$ in PBS) was prepared. Naïve CD $4+\mathrm{T}$ cells were cultured in Th1-differentiating culture medium $(0.5 \mu \mathrm{g} / \mathrm{ml}$ anti-CD28 antibody, $1 \mu \mathrm{g} / \mathrm{ml}$ anti-IL-4 antibody, $5 \mathrm{ng} / \mathrm{ml}$ IL-2, and $10 \mathrm{ng} / \mathrm{ml}$ IL-12 in RPMI 1640 supplemented with $10 \%$ FBS, NEAA, antibiotics, and $55 \mu \mathrm{M} \beta$-mercaptoethanol) (all from R\&D Systems, Minneapolis, MN, USA) for $96 \mathrm{~h}$ according to the Th1 differentiation protocol [18]. Cells were plated in single wells of anti-CD3c-coated 24-well culture dishes for $96 \mathrm{~h}$. The cells were then washed twice with PBS and cocultured with HMCs for $48 \mathrm{~h}$.

2.5. Flow Cytometry (FCM) Analysis. For the staining of cell surface molecules, the cells were suspended in staining buffer (FBS) (BD Pharmingen, San Diego, CA, USA) and stained with saturating concentrations of antibodies against HLADR, human CD40, human CD80, human ICAM-1, and mouse MHC class II (Miltenyi Biotec). The proportions of Th1 cells $(\mathrm{IFN}-\gamma+)$, Th2 cells (IL-4+), Th17 cells (IL-17+), and Treg cells (CD25+ and FOXP3+) were determined by FCM. The cells were activated with $50 \mathrm{ng} / \mathrm{ml}$ phorbol-12myristate-13-acetate (PMA, Sigma-Aldrich), $250 \mathrm{ng} / \mathrm{ml}$ ionomycin (Sigma-Aldrich), and $1 \mu \mathrm{g} / \mathrm{ml}$ Brefeldin A (BD Pharmingen) for $4 \mathrm{~h}$ at $37^{\circ} \mathrm{C}$ in a $5 \% \mathrm{CO}_{2}$ atmosphere. The cells were then stained with antibodies against CD4 and CD25 (Miltenyi Biotec) for $15 \mathrm{~min}$ at room temperature. After cell fixation with $2 \%$ paraformaldehyde and permeabilization with $0.1 \%$ Triton X-100, intracellular antigens were stained with saturating concentrations of antibodies against IFN- $\gamma$, IL-4, IL-17, and FOXP3 (Miltenyi Biotec). FCM quantification of absolute cell numbers was performed using a Beckman Coulter flow cytometer (Miami, FL, USA).

2.6. Antigen-Processing Assays. To analyse the processing of soluble antigens, $40 \mu \mathrm{g} / \mathrm{ml}$ DQ-ovalbumin (DQ-OVA) (Invitrogen) was used. HMCs were stimulated with or without $50 \mathrm{ng} / \mathrm{ml} \mathrm{IFN}-\gamma$ for $48 \mathrm{~h}$ and then incubated with DQ-OVA for $24 \mathrm{~h}$ and $48 \mathrm{~h}$ at $37^{\circ} \mathrm{C}$; the cells were then washed three times with ice-cold PBS, similar to the previously described 
TABLE 1: List of primers used in reverse transcriptase-polymerase chain reaction.

\begin{tabular}{lcc}
\hline Name & Sense primer $\left(5^{\prime}-3^{\prime}\right)$ & Antisense primer $\left(5^{\prime}-3^{\prime}\right)$ \\
\hline HLA-DP & CACCAACCTGATCCGTAA & GACTGTGCCTTCCACTCC \\
HLA-DQ & TCTACCGCTGCTACCAAT & CCACAAGACAAATGAGGG \\
HLA-DR & GGCTTGAAGAATTTGGAC & TGATCGGAGTATAGTTGGA \\
ICAM-1 & GCAAGAAGATAGCCAACCA & TGCCAGTTCCACCCGTTC \\
CD 80 & CCACCTTGCCCTTTACGT & GCCCACCATATTCCTCTA \\
TGF- $\beta$ & TGTCACGGCAGCCGAATT & CCTGGAGCACCTGATAAACG \\
IL-1A & TGACGACGCACTTGTAGC & TCAGTCTTCTTCGCCTTT \\
IL-4 & GCAGTTCCACAGGCACAA & TGGTTGGCTTCCTTCACA \\
IL-6 & GGAGACTTGCCTGGTGAA & ACAGCTCTGGCTTGTTCC \\
IL-12A & CTCCAAACCGTTGTCATT & AATAGTCCCATCCTTCTTT \\
IL-17 & CACCATGTGGCCTAAGAG & AGTCCGAAATGAGGCTGT \\
IL-23A & AGCCAGATTTGAGAAGAAG & GCAACAGCAGCATTACAG \\
CCL2 & AGAATCACCAGCAGCAAG & GGAATCCTGAACCCACTT \\
NFB $B$ & ACTGGAAGCACGAATGAC & CAAATAGGCAAGGTCAGG \\
GAPDH & ACAACTTTGGTATCGTGGAA & CACAGTCTTCTGGGTGGC \\
\hline
\end{tabular}

protocol [19], and the cells were analysed via immunofluorescence and FCM [20].

2.7. OT-II Cell Stimulation Assays. For the stimulation assays, defined MMC populations treated with or without IFN $-\gamma$ and LPS-treated DCs (JAWSII) were cultured for 2 days in the presence or absence of $1 \mathrm{mg} / \mathrm{ml}$ ovalbumin (OVA 323-339 peptide) (Sigma-Aldrich). The cells were intensively washed at least three times with PBS, and naïve CD4+ cells purified from OT-II mice were added at a ratio of $1: 10$. For the assessment of T lymphocyte DNA synthesis, an EdU solution was added $24 \mathrm{~h}$ prior to cell harvesting. After $48 \mathrm{~h}$ of coculture, the CD4+ cells were collected and evaluated using a Click-iT $^{\mathrm{TM}}$ EdU Flow Cytometry Assay Kit (Invitrogen) according to the manufacturer's instructions. The CD4+ cells were analysed using a Beckman flow cytometer [21].

2.8. Real-Time PCR. Total RNA from mesangial cells or CD4 $+\mathrm{T}$ cells was isolated using the TRIzol Reagent (Invitrogen) according to the manufacturer's instructions. cDNA was synthesized with a ProtoScript II First-Strand cDNA Synthesis Kit (New England Biolabs (NEB), Beverly, MA, USA). RTPCR was performed in triplicate using the SYBR Select Master Mix (Life Technologies, California, USA) and an Applied Biosystems 7500 Real-Time PCR system (ABI, Foster City, CA, USA). The threshold cycle (CT) values for target- and GAPDH-specific fragment amplification were determined with the ABI PRISM SDS7500 software, and the delta-CT values were calculated. Primers were used for the following genes (Table 1): HLA-DP, HLA-DQ, HLA-DR, ICAM-1, CD80, TGF- $\beta$, IL-1A, IL-4, IL-6, IL-12A, IL-17, IL-23A, CCL2, NF $\kappa \mathrm{B}$, and GAPDH.

2.9. Western Blotting. The proteins from the cells were resolved on SDS-PAGE gels, transferred onto nitrocellulose membranes, and immunoblotted with antibodies against HLA-DR, ICAM-1, CD80, IL- $1 \alpha$, IL-6, NF $\kappa$ B, CCL2, and $\beta$-actin (Abcam, Cambridge, MA, USA). Secondary antibod- ies were then applied, and the signals were detected using a ChemiDoc-It 600 Imaging System (UVP, Upland, USA).

2.10. ELISA. The levels of the secreted chemokines TGF- $\beta$, IFN- $\gamma$, IL-4, IL-6, IL-10, IL-12, IL-17, and IL-23 in culture supernatants were measured using Quantikine ELISA kits (R\&D Systems) according to the manufacturer's recommended protocol. The absolute concentration of each sample was calculated based on the measured optical density of the sample using a standard curve.

2.11. Statistical Analysis. The results are expressed as the means and standard errors of the mean (SEMs). The statistical analyses were performed with Student's $t$-test or one-way analysis of variance (ANOVA) followed by Tukey's HSD post hoc test, and $P$ values $<0.05$ were considered significant. The SPSS 19.0 software (IBM, Armonk, NY, USA) was used for the statistical analyses.

\section{Results}

3.1. Activated HMCs Express APC Surface Markers and Costimulatory Molecules. Because APCs can mature, as indicated by the upregulation of characteristic surface molecules, we analysed their surface molecule expression. To test the response of HMCs to stimulation with IFN- $\gamma$, which is an important inflammatory cytokine that is mainly produced by effector T cells, HMCs were exposed to IFN- $\gamma$ for $48 \mathrm{~h}$ of culture. HMCs expressed very low mRNA levels of the APC surface markers and the costimulatory molecules HLA-DP, HLA-DQ, HLA-DR, ICAM-1, and CD80. Exposure to IFN- $\gamma$ markedly enhanced HLA-DP, HLA-DQ, HLA-DR, ICAM-1, and CD80 mRNA expression in HMCs (Figure 1(a)). A significant increase in MHC-II (HLA-DR), CD80, and ICAM-1 protein expression in the IFN- $\gamma$-treated HMCs was also observed via western blotting analysis compared with that in the controls (Figure 1(b)). Furthermore, we performed a flow cytometric analysis of HMC surface 
HLA-DP
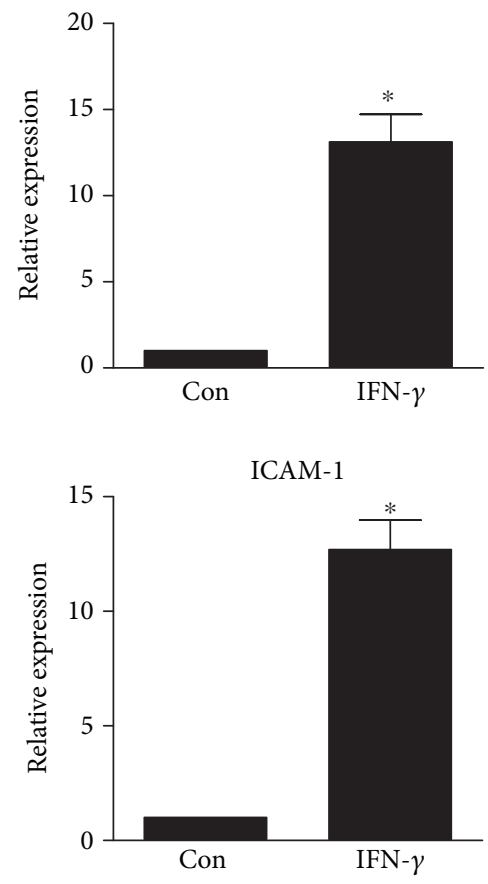

HLA-DQ

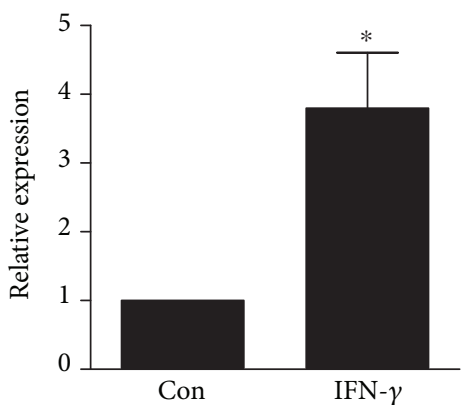

CD80

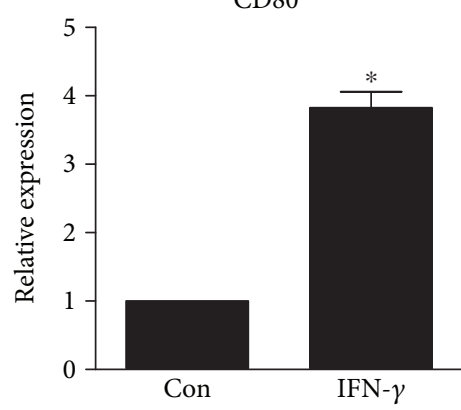

(a)
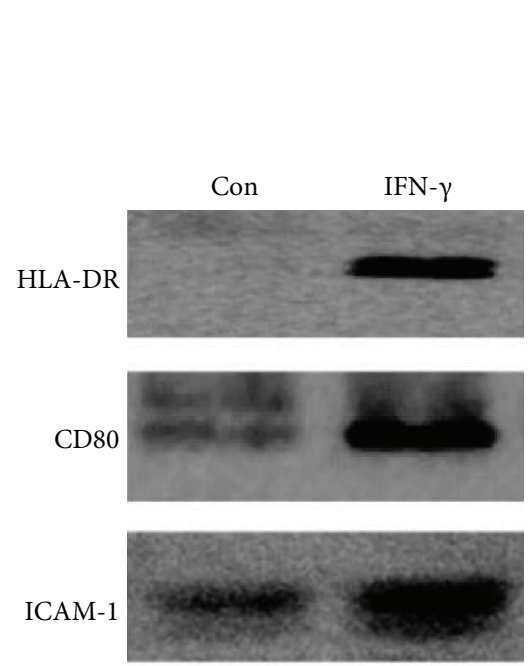

$\beta$-Actin

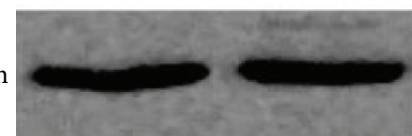

(b)
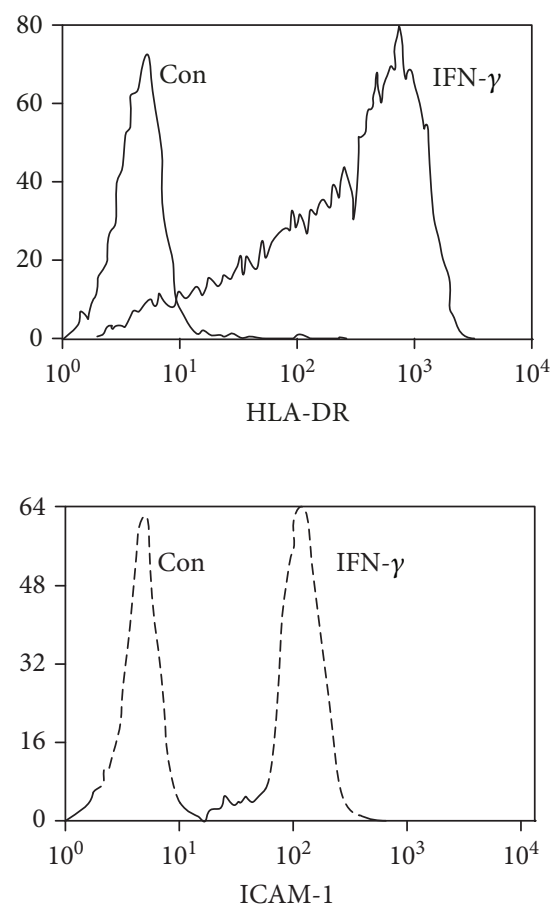
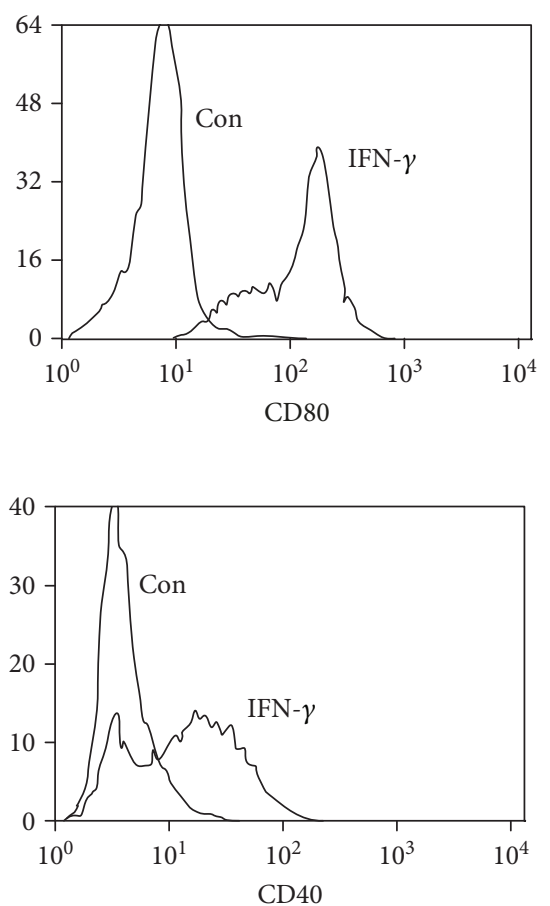

(c)

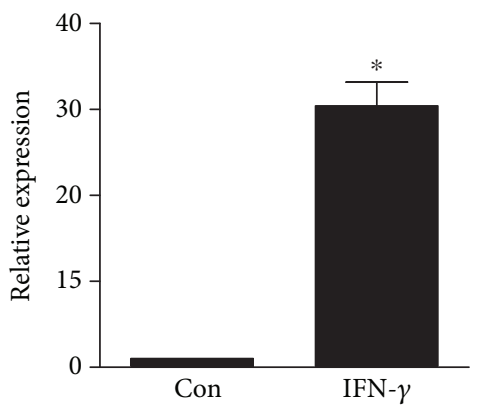



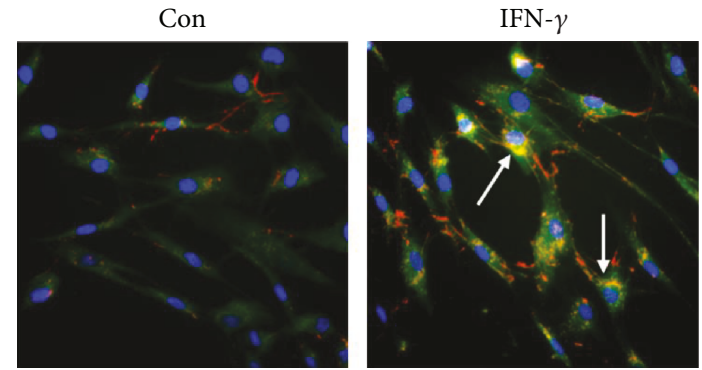

(a)

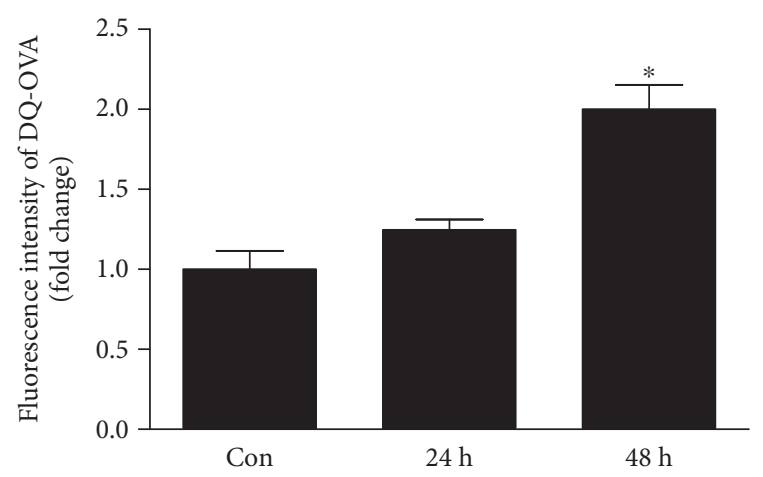

(b)

FIgURE 2: Activated HMCs process antigen. (a) HMCs were treated with or without IFN- $\gamma$ for $48 \mathrm{~h}$, incubated with DQ-OVA for $48 \mathrm{~h}$ at $37^{\circ} \mathrm{C}$ in medium, washed, fixed, and stained with DAPI. The arrows indicate DQ-OVA processing analysed via confocal microscopy. (b) HMCs were pretreated with IFN- $\gamma$ or medium alone for $48 \mathrm{~h}$, incubated for 24 and $48 \mathrm{~h}$ with fluorochrome-labelled ovalbumin (DQ-OVA), and analysed via flow cytometry. The data in (b) were analysed by one-way analysis of variance (ANOVA) followed by Tukey's HSD post hoc test. The data are representative of three independent experiments, and the error bars represent the means \pm SEMs. Con: HMCs treated without IFN- $\gamma .{ }^{*} P<0.05$ vs. Con.

proteins. IFN- $\gamma$-treated HMCs expressed the antigenpresenting molecule MHC-II (HLA-DR) and costimulatory molecules, such as CD80, ICAM-1, and CD40, which are characteristic markers of professional APCs (Figure 1(c)). Collectively, these results show that HMCs express APC surface markers and costimulatory molecules.

\subsection{Activated HMCs Have the Ability to Process Antigen In} Vitro. To further analyse the antigen-processing function of cells, we used DQ-OVA, a self-quenching conjugate that upon proteolysis produces fluorescent DQ-OVA-derived peptides that can be quantified using fluorescence-based techniques. We first examined the distribution of DQ-OVA in cells through confocal microscopy. The images showed that IFN- $\gamma$-treated HMCs exhibited stronger fluorescence signals than untreated HMCs (Figure 2(a)). The DQ-OVA peptide-associated fluorescence was also quantified by FCM. The intensity of DQ-OVA-stained HMCs treated with IFN- $\gamma$ was markedly increased compared with that of untreated HMCs (Figure 2(b)). Taken together, these findings indicate that IFN- $\gamma$-treated HMCs are capable of processing antigen.
3.3. MMCs Activate Nä̈ve CD4+ OT-II T Cells through MHC-II Presentation. We subsequently aimed to elucidate the antigen presentation function of mesangial cells with regard to $\mathrm{CD} 4+\mathrm{T}$ cell stimulation. To this end, we isolated antigen-specific naïve CD4+ T cells from OT-II T cell receptor- (TCR-) transgenic mice. Because the naïve CD4+ OT-II T cells were isolated from mice, we used MMCs for coculture, and the naïve CD4+ OT-II T cells were cocultured with LPSmatured DCs as APCs. IFN- $\gamma$-treated MMCs expressed the antigen-presenting molecule MHC-II, which is a characteristic marker of professional APCs (Figure 3(a)). MMCs or DCs (JAWSII) were pulsed with ovalbumin (OVA), which is specifically recognized by CD4+ OT-II T cells, and subsequently cocultured with naïve CD4+ OT-II T cells. CD4+ OT-II T cells were specifically stimulated by IFN- $\boldsymbol{\gamma}$-treated MMCs or LPS-treated DCs presenting the OVA peptide in the context of MHC-II. OVA-specific CD4 T cell proliferation was induced by IFN- $\gamma$-treated MMCs or LPS-treated DCs, and the direct pulsing of CD4+ T cells with OVA in the absence of IFN- $\gamma$-treated MMCs or LPS-treated DCs did not result in proliferation (Figure 3(b)). To determine the effect of IFN- $\gamma$-stimulated MMCs on the activation of naïve CD4+ $\mathrm{T}$ cells, we measured $\mathrm{T}$ cell cytokine markers, including IFN- $\gamma$ (Th1 cells), IL-4 (Th2 cells), IL-10 (Th2 cells), and IL-17 (Th17 cells). The IFN- $\gamma$ and IL-4 levels in the culture medium of CD4+ T cells activated by IFN- $\gamma$-stimulated MMCs were significantly increased compared with those found for the other groups. However, these CD4+ T cells produced very little IL-10 or IL-17 (Figure 3(c)). In conclusion, IFN- $\gamma$-treated MMCs represent professional APCs that can present peptides to CD4+ T cells and activate CD4+ T cell proliferation in vitro.

3.4. Activated HMCs Drive the Differentiation of Naïve CD4+ $T$ Cells into Th1 Effectors. To assess the effect of activated mesangial cells on T cells, we assayed the properties of T cells activated by IFN- $\gamma$-stimulated HMCs. First, we examined the cytokine expression levels of HMCs under basal and IFN- $\gamma$-stimulated conditions (Figure 4(a) for mRNA and Figure 4(b) for protein). HMC activation by IFN- $\gamma$ for $48 \mathrm{~h}$ resulted in increases in IL-6, IL-12A, and IL-23A mRNA expression (Figure 4(a)). The IL-6, IL-12, and IL-23 protein levels in cell culture supernatants of IFN- $\gamma$-treated HMCs were significantly increased compared with those in supernatants of untreated HMCs (Figure 4(b)). However, there appeared to be no statistically significant difference between IFN- $\gamma$-treated HMCs and control cells with respect to the expression of TGF- $\beta$ and IL-4 (Figures 4(a) and 4(b)). HMCs were activated by IFN- $\gamma$ and subsequently cocultured with naïve CD4+ $\mathrm{T}$ cells for $48 \mathrm{~h}$. To determine the effect of IFN- $\gamma$-stimulated HMCs on the activation of CD4+ T cells, we measured cytokine markers of T cells, including IFN- $\gamma$, IL-4, IL-10, and IL-17. High levels of IFN- $\gamma$ were detected in the culture medium of CD4+ T cells activated by IFN- $\gamma$ stimulated HMCs. The IL- 4 level in the culture medium of CD4+ T cells activated by IFN- $\gamma$-stimulated HMCs was found to be significantly increased compared with that in the other groups, but these CD4+ T cells produced very little IL-10 or IL-17 (Figure 4(c)). Quantitative real-time PCR 


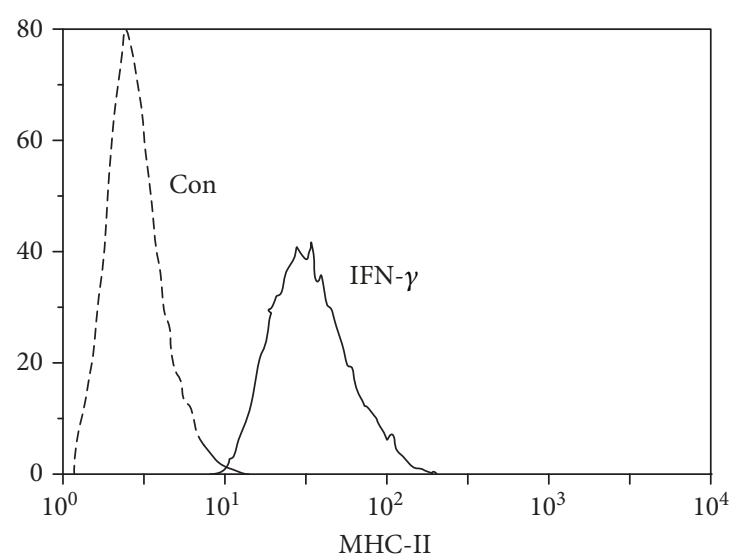

(a)
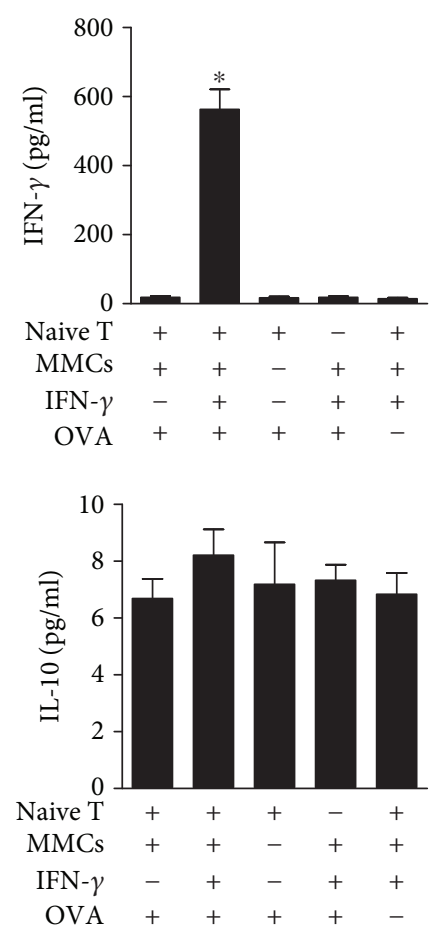

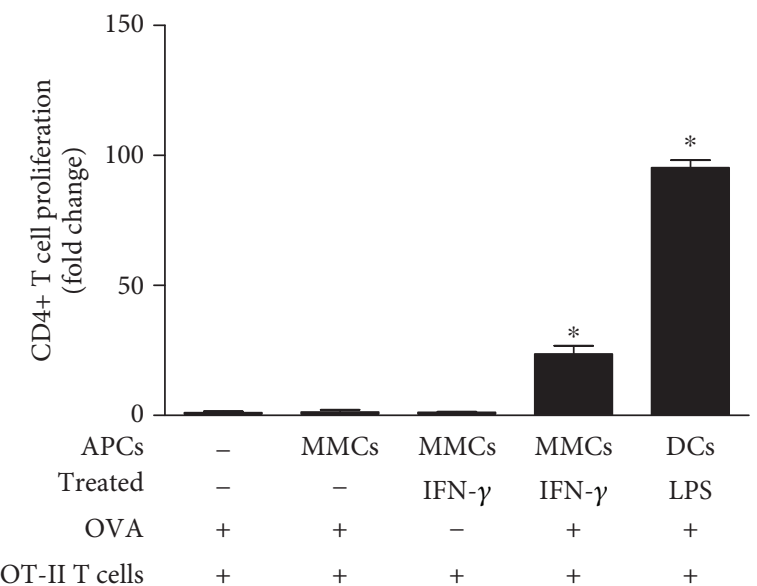

(b)
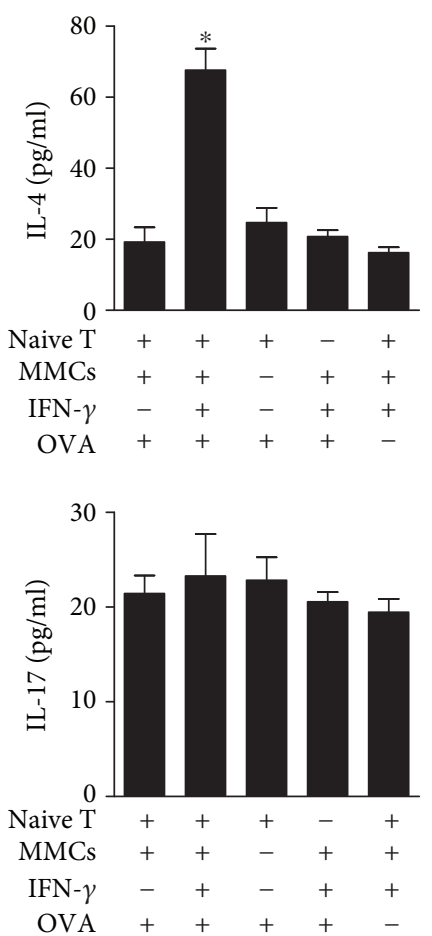

(c)

Figure 3: MMCs activate CD4+ T cells by MHC-II presentation. (a) Flow cytometric analysis of MHC-II molecules expressed on MMCs that were cultured for $48 \mathrm{~h}$ with IFN- $\gamma$ stimulation. (b) IFN- $\gamma$-treated MMCs or LPS-treated DCs were incubated with or without ovalbumin (OVA, $1 \mathrm{mg} / \mathrm{ml}$ ). Subsequently, antigen-pulsed MMCs or DCs were cocultured with naïve CD4+ T cells (OT-II). Additionally, OT-II T cell preparations were incubated with ovalbumin $(1 \mathrm{mg} / \mathrm{ml})$ alone. Two days after stimulation, antigen-specific proliferation was analysed with an EdU assay and detected by FCM. The results are expressed as fold changes in EdU-positive CD4+ T cells (OT-II). (c) MMCs were treated with IFN- $\gamma$ for $48 \mathrm{~h}$, extensively washed, irradiated, and cocultured with naïve CD4+ OT-II T cells and ovalbumin (1 mg/ml) for 48 h. Cytokine expression was analysed via ELISA to determine the expression of IFN- $\gamma$, IL-4, IL-10, and IL-17 in the culture supernatant. The data in (b) and (c) were analysed by one-way analysis of variance (ANOVA) followed by Tukey's HSD post hoc test. The error bars represent the means \pm SEMs, and the graphs are representative of at least three independent experiments with similar results; ${ }^{*} P<0.05$.

demonstrated that the IFN- $\gamma$ and IL-4 levels were increased significantly in CD4+ T cells cocultured with IFN- $\gamma$-stimulated HMCs compared with the levels observed in the control group (Figure 4(d)). CD4+ T cell proliferation was analysed using an EdU assay and detected by FCM, and CD4+ T cell proliferation was found to be induced by IFN- $\gamma$-treated HMCs (Figure 4(e)). Nontreated HMCs induced T cell populations that produced very little IFN- $\gamma$, IL-4, or IL-17, and IFN- $\gamma$-stimulated HMCs induced a significant percentage of IFN- $\gamma$-producing $\mathrm{T}$ cells and IL-4-producing $\mathrm{T}$ cells 

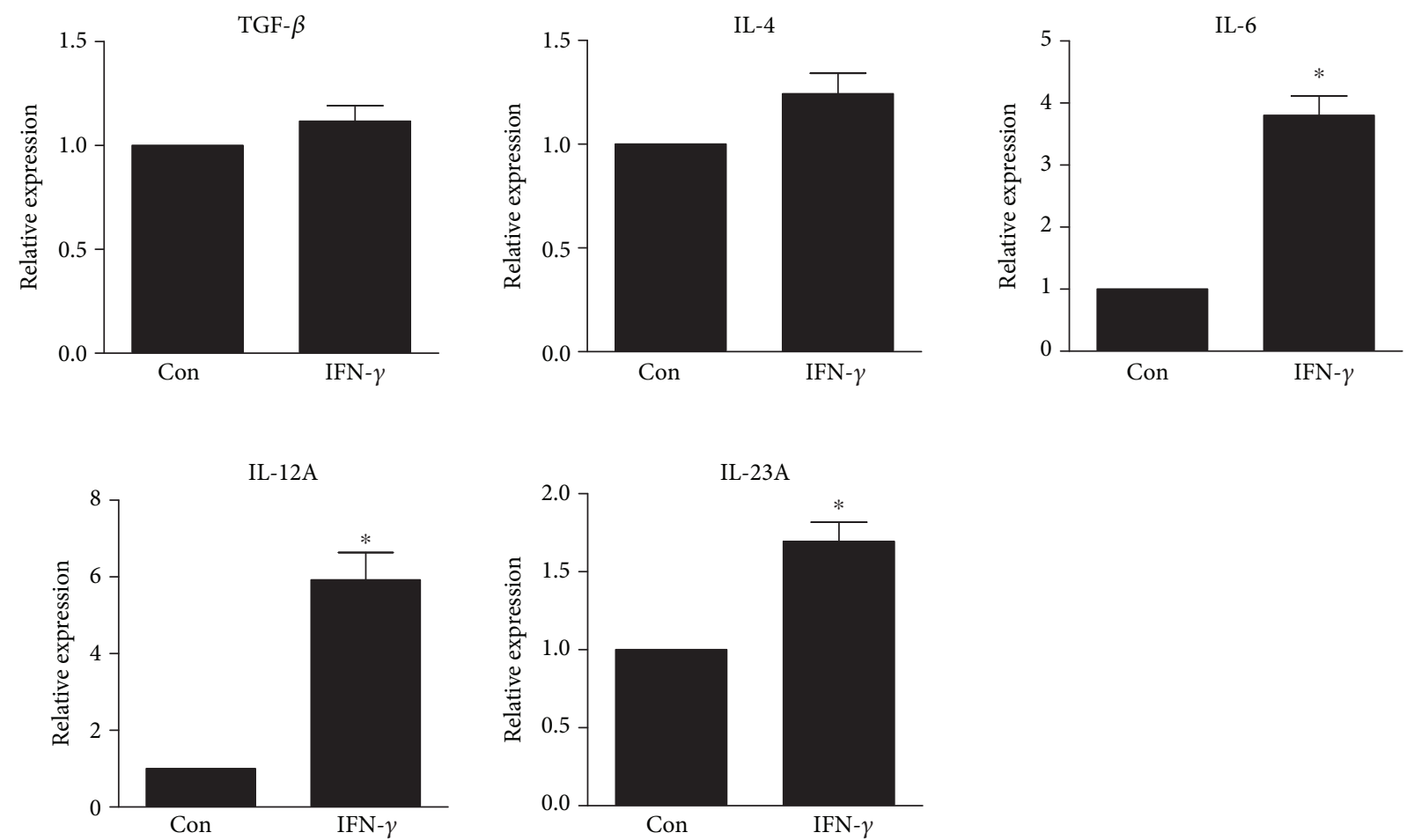

(a)
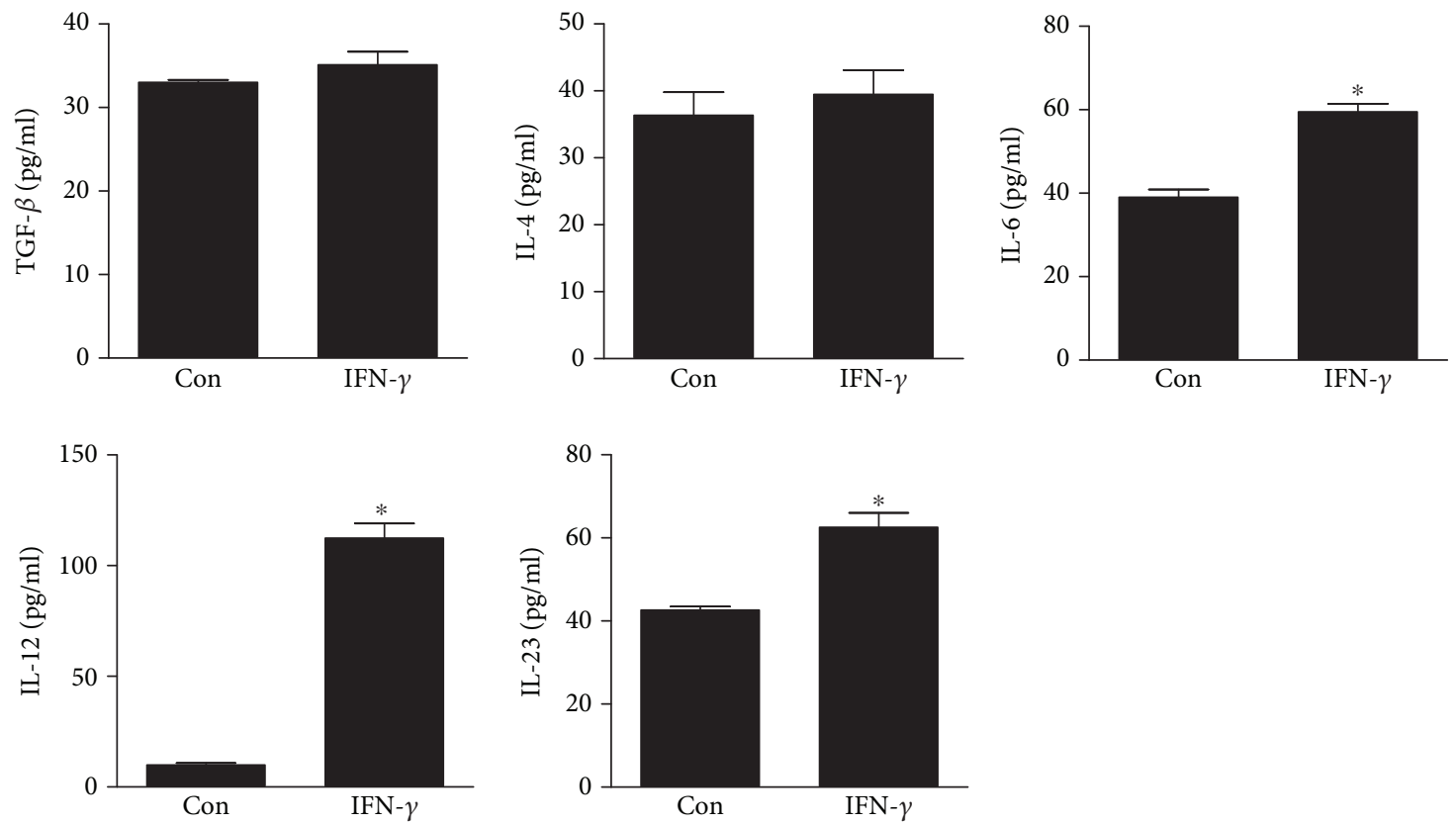

(b)

Figure 4: Continued. 

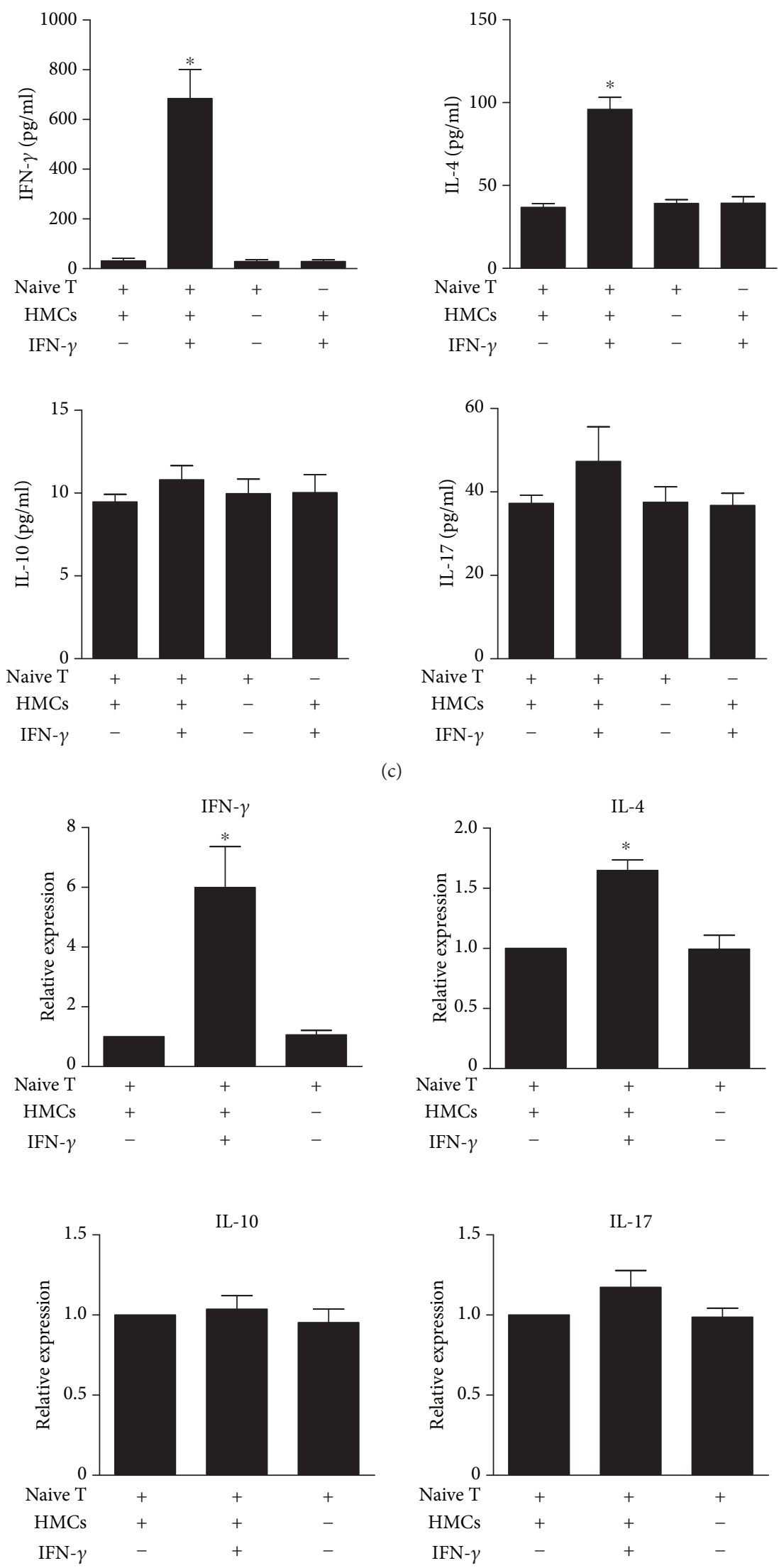

(d)

FIgURE 4: Continued. 


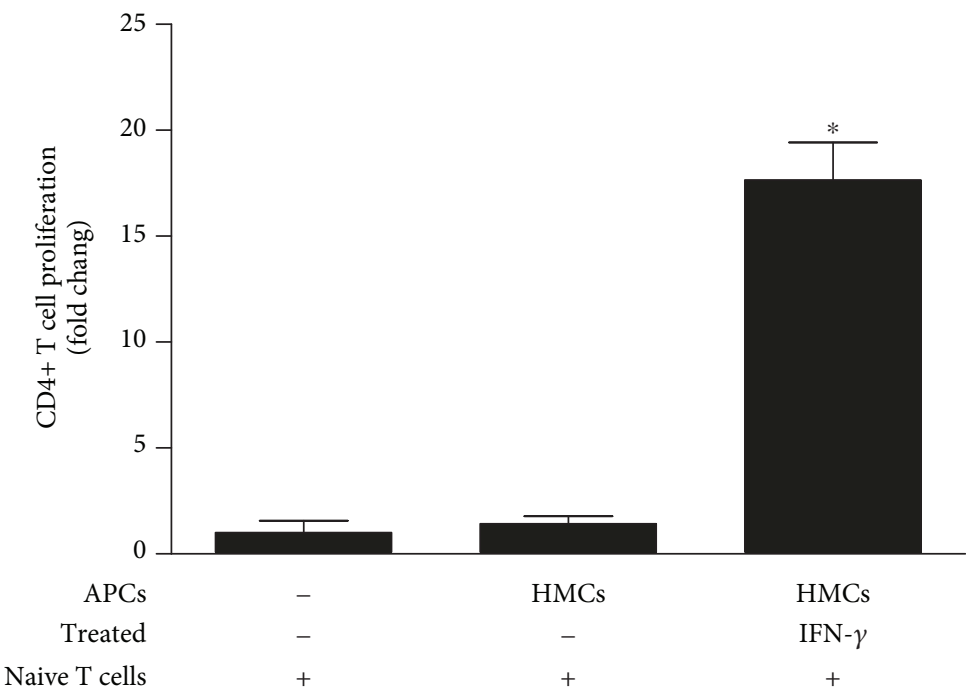

(e)
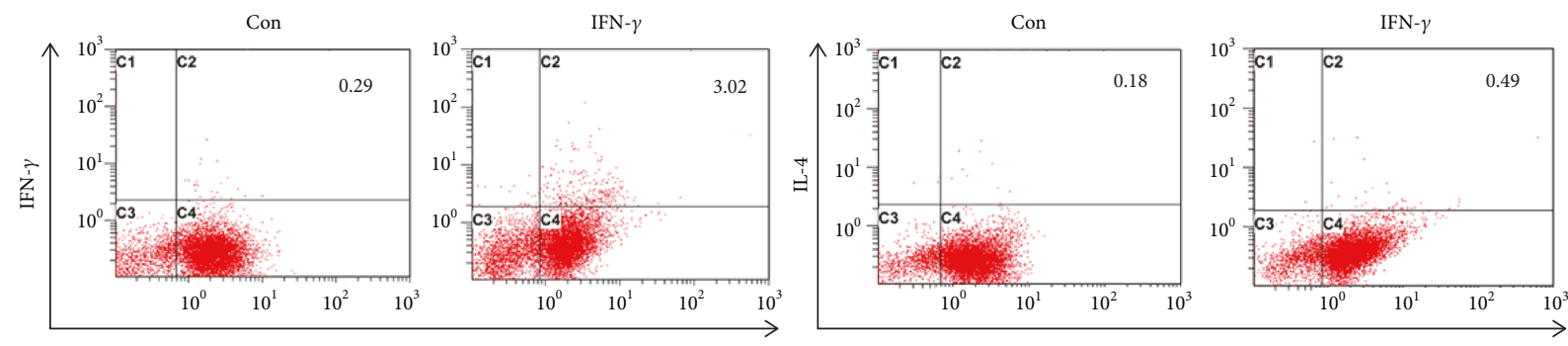

$\mathrm{CD} 4$

$\mathrm{CD} 4$
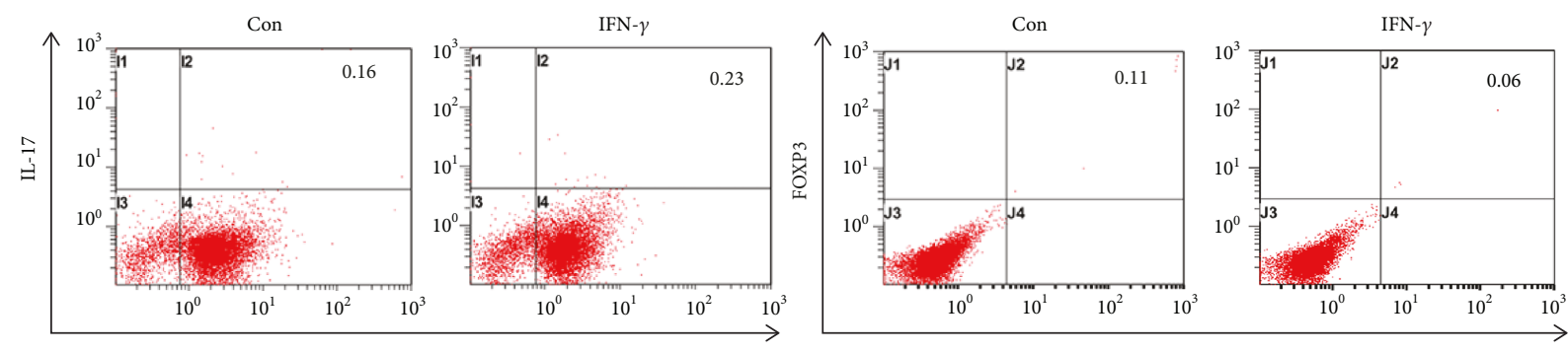

(f)

FIgURE 4: Activated HMCs induce the differentiation of naïve CD4+ T cells. (a) The mRNA expression of TGF- $\beta$, IL-4, IL-6, IL-12A, and IL$23 \mathrm{~A}$ in HMCs treated with IFN- $\gamma$ for $48 \mathrm{~h}$ was analysed by RT-PCR. (b) The protein expression of TGF- $\beta$, IL-4, IL-6, IL-12, and IL-23 in cell culture supernatants from HMCs treated with IFN- $\gamma$ for $48 \mathrm{~h}$ was analysed via ELISA. (c) HMCs were treated with IFN- $\gamma$ for 48 h, extensively washed, irradiated, and cocultured with naïve CD4+ T cells for $48 \mathrm{~h}$. ELISA was used to determine the expression of the cytokines IFN- $\gamma$, IL-4, IL-10, and IL-17 in the culture supernatant. (d) HMCs were treated with IFN- $\gamma$ for $48 \mathrm{~h}$, extensively washed, irradiated, and cocultured with naïve CD4+ T cells for $48 \mathrm{~h}$. The mRNA expression of IFN- $\gamma$, IL-4, IL-10, and IL-17 in CD4+ T cells was analysed via RT-PCR. (e) HMCs were treated with IFN- $\gamma$ for $48 \mathrm{~h}$, extensively washed, irradiated, and cocultured with naïve CD4+ T cells for $48 \mathrm{~h}$. Two days after stimulation, proliferation was analysed using an EdU assay and detected by FCM. The results are expressed as fold changes in EdUpositive CD4+ T cells. (f) HMCs cultured alone or in the presence of IFN- $\gamma$ were used to activate naïve CD4+ T cells. The differentiation of activated T cells into Th1 (IFN- $\gamma+$ ), Th2 (IL-4+), Th17 (IL-17+), or Treg (FOXP3+, CD25+) effectors was assessed via intracellular staining and flow cytometry after $48 \mathrm{~h}$. The data in (a) and (b) were analysed by Student's $t$-test, and the data in (c), (d), and (e) were analysed by one-way analysis of variance (ANOVA) followed by Tukey's HSD post hoc test. The data are representative of three independent experiments, and the error bars represent the means \pm SEMs. Con: HMCs treated without IFN- $\gamma \cdot{ }^{*} P<0.05$.

(Figure 4(f)). Coculture significantly increased the differentiation of IFN- $\gamma+$ Th1 and IL-4+ Th2 cells; therefore, this strategy effectively induces IFN- $\gamma+$ Th1 over IL- $4+$ Th2 cells. These data suggest that naïve CD $4+\mathrm{T}$ cells activated by IFN$\gamma$-treated HMCs predominantly undergo Th1 differentiation.
3.5. Th1 Cells Lead to HMC Activation. To further assess the effect of Th1 cells on mesangial cells, we detected the cytokine expression of HMCs that were cocultured with Th1 cells but not treated with IFN- $\gamma$. We used an anti-CD3 $\varepsilon$ antibody and Th1-differentiating culture medium to induce Th0 cell 
polarization to Th1 cells (Figure 5(a)) and then cocultured the $\mathrm{T}$ cells with mesangial cells for $48 \mathrm{~h}$. The IL-1A, IL-6, CCL2, and NF $\kappa \mathrm{B}$ mRNA expression levels were increased significantly in the mesangial cells cocultured with Th1 cells compared with the levels observed in the control group (Figure 5(b)). We also found that the IL-1 $\alpha$, IL-6, CCL2, and $\mathrm{NF} \kappa \mathrm{B}$ protein levels in HMCs cocultured with Th1 cells were increased compared with the levels observed in the control group (Figures 5(c) and 5(d)). These results demonstrate that Th1 cells lead to HMC activation.

\section{Discussion}

Mesangial cells have been recognized as an important factor in the pathogenesis of glomerular injury in many different glomerular diseases [22]. Mesangial cell activation induces distinct phenotypes in response to changes in the glomerular microenvironment [23]. Our study provides evidence showing that activated mesangial cells express the membrane proteins required for antigen presentation and modulate CD4+ T lymphocyte proliferation. Similar properties have been described in hepatic stellate cells and astrocytes, which indicates that under certain circumstances, these cells could play a supporting role in the local regulation of the immune system $[24,25]$. Based on our findings, we propose that mesangial cells play a role in immune function in the kidney.

MHC-II molecules are surface glycoproteins that bind exogenous antigens and present them to TCRs and are considered important markers of APCs. The expression profile of MHC and costimulatory molecules on professional or nonprofessional APCs can greatly influence the magnitude of T cell activation. The Th1 cytokine IFN- $\gamma$ alone or in combination with other cytokines has been reported to induce MHC class II expression in many different cell types [24, 26-28]. IFN- $\gamma$ primarily enhances MHC-II expression by upregulating the expression of MHC class II transactivator (CIITA), a transcriptional coactivator that is essential for MHC-II expression [29]. The upregulation of the MHC class II gene by IFN- $\gamma$ is a critical process in antigen presentation and leads to the activation of $\mathrm{T}$ cell antigen presentation and thereby activation of $\mathrm{T}$ cell-mediated immune reactions [30]. IFN- $\gamma$ induces the expression of a set of early response genes through the formation of a ligand-dependent multimolecular complex containing IFN- $\gamma$ receptor chains ( $\mathrm{a}$ and $\mathrm{b}$ ), Janus tyrosine kinases (Jak1 and Jak2), and the transcription factor Statla [31], which indicates that Statla is critical for CIITA and MHC class II expression in IFN- $\gamma$-induced mesangial cells.

HMCs stimulate CD4+ T cells to proliferate and synthesize cytokines since there is no nominal antigen introduced. IFN- $\gamma$ stimulates human mesangial cells to secrete cytokines such as IL-6, IL-12A, and IL-23, which may stimulate T cell proliferation and cytokine secretion. A subset of human peripheral blood CD4+ T cells can be activated with the combination of IL-12 and IL-18 to produce IFN- $\gamma$ in the absence of any antigenic stimulation [32], suggesting that naïve CD4+ $\mathrm{T}$ cells may participate in innate immunity or amplify adaptive immune responses through cytokine-induced antigen- independent cytokine production. In our experiment, human naïve CD4+ T cells were cocultured with mesangial cells that were not stimulated by IFN- $\gamma$ and did not release cytokines or proliferate. These cytokines were produced only after IFN- $\gamma$ stimulation of mesangial cells, indicating their potential specific involvement in the indirect interactions of IFN$\gamma$-stimulated HMCs and CD4+ T cells. A limitation of the present study is that the HLA genotype of naive human $\mathrm{CD} 4+\mathrm{T}$ cells was not detected. The exact role of MHC molecules in the peripheral survival and proliferation of naïve $\mathrm{T}$ cells is controversial, as some studies have suggested that they are critically required, whereas others have suggested that they are not $[33,34]$. In some cases, MHC molecules signal via the antigen-specific portions of the TCR to initiate productive immune responses, whereas in other cases, they may signal through other molecules, such as CD4 and CD2, which can occur independent of TCR signalling [35]. Numerous in vitro studies have demonstrated that $\mathrm{T}$ cells are dependent on cytokines for antigen-induced proliferation. The cell-cell interactions between $\mathrm{T}$ cell and antigenpresenting cells (APCs) have been extensively studied using the proliferation assay in which $\mathrm{T}$ cell populations from primed animals proliferate when reexposed to the priming antigen. Because human cells lack an ideal specific antigen for coculture, we selected mouse CD4+ $\mathrm{T}$ cells and mesangial cells from the C57BL/6 background and OVA antigen coculture to study whether mesangial cells have antigen-presenting functions. The current study has provided the groundwork for understanding the nature of the interactions (indirect and direct) between mesangial cells and $\mathrm{T}$ cells.

Previous studies have detected the expression of antigen presentation molecular markers in mesangial cells [11], but few have explored the APC function of these cells. Human and murine mesangial cells were used in our study. Mesangial cells from different species have similar effects and can be induced by IFN- $\gamma$ to express antigen-presenting molecular markers and secrete cytokines. With the aim of elucidating the antigen presentation function of mesangial cells, mesangial cells presenting the OVA antigen to activate naïve CD4 + OT-II T cells were detected. The evidence for the APC function of mesangial cells relies on the coculture of mesangial cells, ovalbumin, and naïve CD4+ OT-II T cell preparations. Because the CD4+ OT-II cells were obtained from a C57BL/6 mouse source, we selected mouse mesangial cells for the coculture with the CD4+ OT-II cells. Activated mesangial cells processed the ovalbumin protein for antigen-specific CD4+ OT-II T cell stimulation. OT-II mice express $\alpha$ - and $\beta$-chains of the T cell receptor and CD4 coreceptors that are specific for recognizing chicken ovalbumin 323-339 presented by MHC-II molecules; thus, these mice are useful for in vitro and in vivo studies of $\mathrm{T}$ cell biology, such as those investigating TCR-ligand interactions, antigen presentation, and $\mathrm{T}$ cell activation [36]. Ovalbumin-specific CD4+ OT-II T cell activation is induced by renal tubular epithelial cells or podocytes, which act as nonprofessional APCs to trigger specific T cell responses in the kidney $[37,38]$.

Immune-mediated damage to glomerular structures is largely responsible for the pathology associated with the 


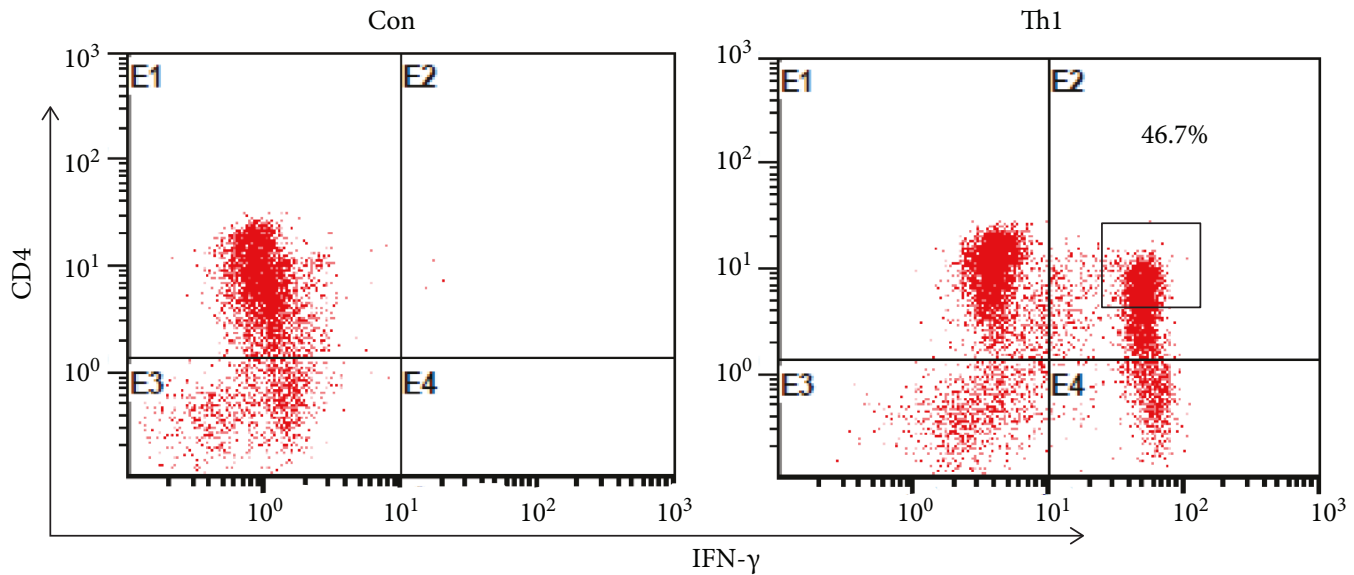

(a)
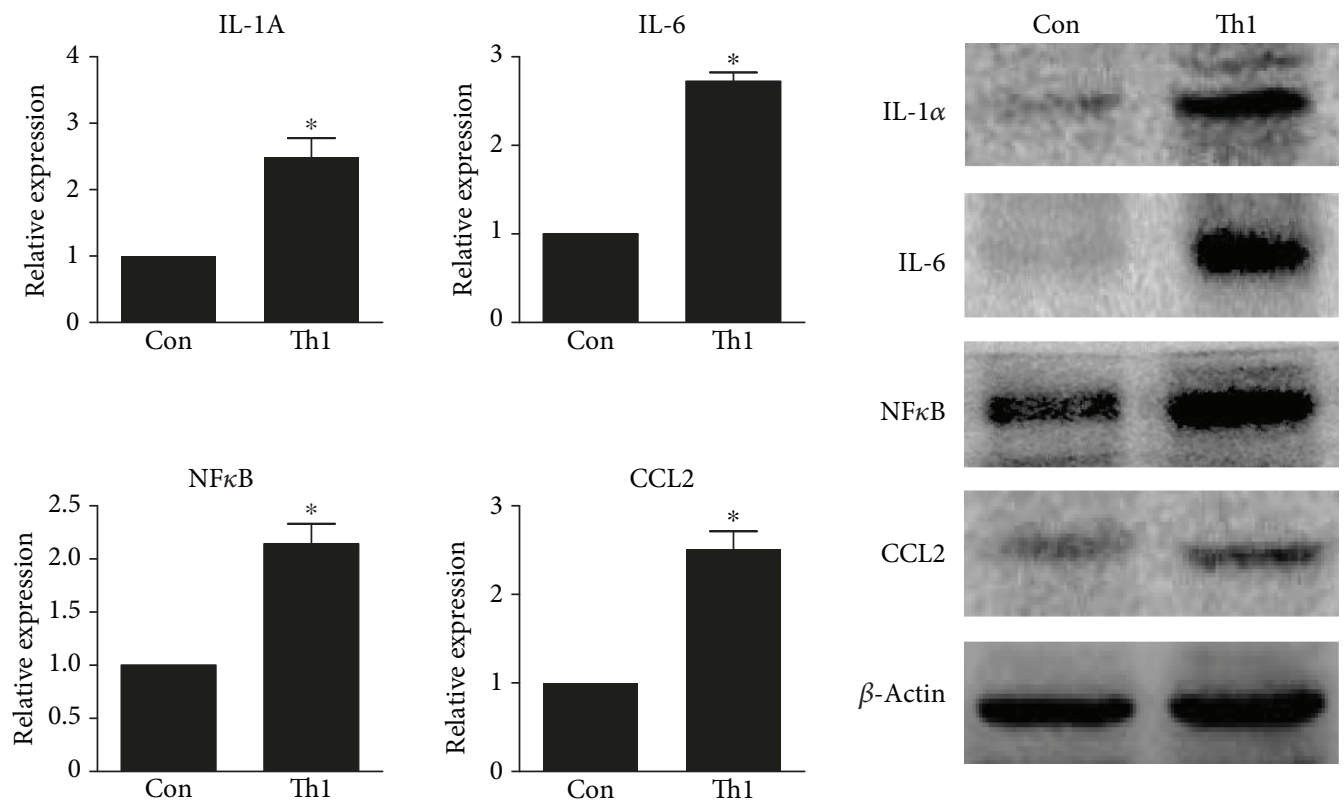

(b)

(c)

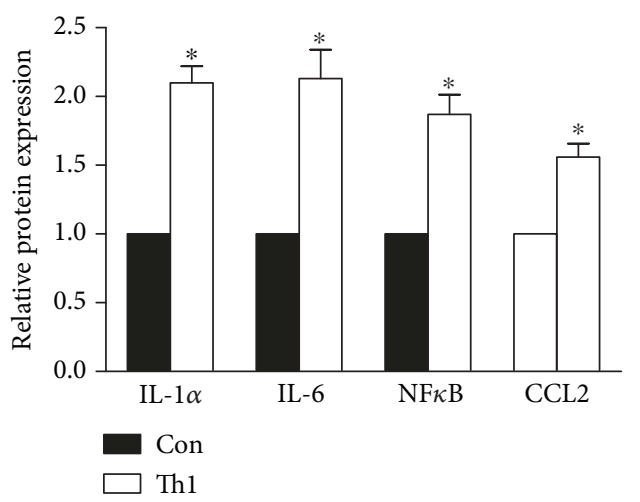

(d)

FIGURE 5: Th1 cells mediate proinflammatory effects in HMCs. (a) Naïve CD4+ T cells develop into Th1 cells after stimulation with anti-CD3 $\varepsilon$ antibody and Th1-differentiating culture medium. (b) Cytokine expression was analysed via RT-PCR, and the results revealed that Th1 cells induced markedly increased IL-1A, IL-6, CCL2, and NF $\kappa$ B mRNA expression in HMCs. (c) Representative western blots showing the protein expression levels of IL- $1 \alpha$, IL-6, CCL2, and NF $\kappa$ B in mesangial cells after interaction with Th1 cells for 48 h; $\beta$-actin was used as the loading control. (d) The relative quantitation of IL- $1 \alpha$, IL-6, CCL2, and NF $\kappa$ B protein expression in each group was determined by western blot analysis; $\beta$-actin served as the internal reference. The data in (b) and (d) were analysed using Student's $t$-test. The data are representative of three independent experiments, and the error bars represent the means \pm SEMs. Con: HMCs cocultured with Th0 cells. ${ }^{*} P<0.05$ vs. Con. 
majority of glomerular diseases [39]. Genetically modified immune responses to infection and self-antigens initiate most forms of GN by generating pathogen- and dangerassociated molecular patterns that stimulate Toll-like receptors and complement [40]. The presence of immune cells and their mediators in the glomerulus is a strong indicator of infection or a developing pathologic process. The innate immune responses activate circulating monocytes and resident glomerular cells to release inflammatory mediators and initiate adaptive, antigen-specific immune responses that collectively damage glomerular structures. All subsets of $\mathrm{T}$ cells, including CD4 helper cells of the Th1, Th2, and T regulatory (Treg) lineages, have been implicated in GN, and IL17-producing Th17 cells induce inflammation. Studies of experimental glomerulonephritis have shown that Th1 and Th17 cells contribute to glomerular damage [41]. Th2 cells play a role in glomerular disease by activating B cells, which produce antibodies that contribute to glomerular injury through their deposition as immune complexes in the glomerulus. A unique pathway termed cross-presentation allows DCs to present exogenous antigens via MHC class I molecules to CD8+ T cells. Following activation, CD8+ T cells differentiate into cytotoxic $\mathrm{T}$ cells that also play a role in glomerular disease. $\mathrm{T}$ cells are attracted through mechanisms involving chemokines and their receptors and release cytokines, such as IFN- $\gamma$, TNF- $\alpha$, IL-4, and IL-17, which induce other cells to produce additional proinflammatory chemokines that activate resident glomerular cells, including mesangial cells. Mesangial cells play a critical role in the initiation of glomerular inflammation through their ability to detect and respond to immune complexes, aberrantly glycosylated IgA, oxidative stress, cytokines, chemokines, and lytic toxins, including the membrane attack complex. In response to these signals, mesangial cells produce inflammatory cytokines and chemokines that recruit and activate inflammatory cells $[42,43]$. Once activated, macrophages and neutrophils perpetuate glomerular damage by releasing inflammatory cytokines and chemokines that recruit additional inflammatory cells into the glomerulus, and this effect activates mesangial cells, stimulates their dedifferentiation, and induces the release of growth factors that drive hypertrophy and mesangial expansion.

CD4+ T cells play an important role in mesangial proliferative glomerulonephritis (MsPGN) [44, 45]. CD4+ T cells that recognize specific antigens deposited in the glomerular mesangium cause glomerulonephritis-like kidney injury. CD4+ T cell-mediated inflammation induces mesangial cell activation and increases in glomerular MCP1 and fibronectin, which shows that $\mathrm{T}$ cells reactive to antigens in the mesangium are sufficient for the initiation of glomerular pathology [12]. Anti-CD5 mAb treatment suppresses CD4+ $\mathrm{T}$ cell recruitment into glomeruli and reduces proteinuria and mesangial injury [46]. Th1 cells mediate proinflammatory cellular immunity, and their ability to secrete IFN- $\gamma$ and activate mesangial cells is important in the progression of MsPGN [47]. HMCs stimulated by IgA1 can produce CCL20 and consequently recruit inflammatory Th17 cells to the kidneys to induce further lesions in IgA nephropathy [43]. The immune balance towards the proinflamma-
tory/Th1 phenotype in mesangial cells might initiate and/or prolong inflammation, resulting in glomerular disease. A previous study reported that high glucose stimulation increases proinflammatory/Th1 gene expression but decreases Th2-related gene expression in mesangial cells [48]. Patients with MsPGN have elevated serum IFN- $\gamma$ levels and decreased serum IL-10 levels compared with those in healthy controls [49]. Increased intrarenal gene expression of proinflammatory and Th1 cytokines (IFN- $\gamma$ and IL-2) is associated with glomerular lesions in IgAN [50]. The cytokine balance is fundamentally skewed towards a Th1 phenotype in MsPGN patients, and immunoregulatory factors counter this shift in the Th1/Th2 balance and thereby produce therapeutic effects $[49,51]$. These results support the dominance of the contribution of the interaction between Th1 cells and mesangial cells to the pathogenesis of MsPGN.

\section{Conclusions}

In summary, we provide evidence showing that activated mesangial cells express the molecules necessary for antigen presentation and modulate lymphocyte proliferation. Local cell-to-cell interactions mediated by mesangial cells and $\mathrm{T}$ cells are essential for sustaining the inflammatory response in a variety of glomerulonephritides. Therefore, mesangial cells might participate in the immune function of the kidney.

\section{Data Availability}

The data used to support the findings of this study are available from the corresponding author upon request.

\section{Conflicts of Interest}

The authors have no conflicts of interest to disclose.

\section{Authors' Contributions}

Xiangmei Chen and Zhe Feng conceptualized the study, designed the experiments, and revised the article. Hongyu $\mathrm{Yu}$ and Qinggang $\mathrm{Li}$ analysed the data, interpreted the results, and drafted the article. Hongyu Yu, Shaoyuan Cui, Yan Mei, Lingling Wu, Shuwei Duan, Bo Fu, and Li Zhang performed the experiments. Guangyan Cai and Hanyu Zhu helped perform the analyses and prepare the manuscript.

\section{Acknowledgments}

This work was supported by grants from Programs of the National Natural Science Foundation of China (81330019), the National Basic Research Program of China (2015CB553605), the National Key Research and Development Program of China (2016YFC1305502), and the Science and Technology Project of Beijing, China (D181100000118002 and D181100000118004). 


\section{Supplementary Materials}

Supplementary Figure 1 (S1): isolation of naïve CD4+ T cells by magnetic microbeads. (Supplementary Materials)

\section{References}

[1] T. Robert, L. Berthelot, A. Cambier, E. Rondeau, and R. C. Monteiro, "Molecular insights into the pathogenesis of IgA nephropathy," Trends in Molecular Medicine, vol. 21, no. 12, pp. 762-775, 2015.

[2] R. J. Wyatt and B. A. Julian, "IgA nephropathy," The New England Journal of Medicine, vol. 368, no. 25, pp. 2402-2414, 2013.

[3] C. Gomez-Guerrero, P. Hernandez-Vargas, O. Lopez-Franco, G. Ortiz-Munoz, and J. Egido, "Mesangial cells and glomerular inflammation: from the pathogenesis to novel therapeutic approaches," Current Drug Target -Inflammation \& Allergy, vol. 4, no. 3, pp. 341-351, 2005.

[4] S. Gauer, J. Yao, H. O. Schoecklmann, and R. Bernd Sterzel, "Adhesion molecules in the glomerular mesangium," Kidney International, vol. 51, no. 5, pp. 1447-1453, 1997.

[5] D. Odobasic, A. R. Kitching, T. J. Semple, J. R. Timoshanko, P. G. Tipping, and S. R. Holdsworth, "Glomerular expression of CD80 and CD86 is required for leukocyte accumulation and injury in crescentic glomerulonephritis," Journal of the American Society of Nephrology Jasn, vol. 16, no. 7, pp. 20122022, 2005.

[6] R. Schmitt, A. L. Ståhl, A. I. Olin et al., "The combined role of galactose-deficient IgA1 and streptococcal IgA-binding $\mathrm{M}$ protein in inducing IL-6 and C3 secretion from human mesangial cells: implications for IgA nephropathy," Journal of Immunology, vol. 193, no. 1, pp. 317-326, 2014.

[7] A. Shankar, L. Sun, B. E. K. Klein et al., "Markers of inflammation predict the long-term risk of developing chronic kidney disease: a population-based cohort study," Kidney International, vol. 80, no. 11, pp. 1231-1238, 2011.

[8] H. R. Jang and H. Rabb, "Immune cells in experimental acute kidney injury," Nature Reviews Nephrology, vol. 11, no. 2, pp. 88-101, 2015.

[9] K. Hochheiser, D. R. Engel, L. Hammerich et al., "Kidney dendritic cells become pathogenic during crescentic glomerulonephritis with proteinuria," Journal of the American Society of Nephrology, vol. 22, no. 2, pp. 306-316, 2011.

[10] B. D. G. Evers, D. R. Engel, A. M. C. Böhner et al., “CD103+ kidney dendritic cells protect against crescentic GN by maintaining IL-10-producing regulatory T cells," Journal of the American Society of Nephrology, vol. 27, no. 11, pp. 33683382, 2016.

[11] M. Martin, R. Schwinzer, H. Schellekens, and K. Resch, "Glomerular mesangial cells in local inflammation. Induction of the expression of MHC class II antigens by IFN-gamma," Journal of Immunology, vol. 142, no. 6, pp. 1887-1894, 1989.

[12] Y. Scindia, D. Nackiewicz, P. Dey et al., "Activated CD4+ T cells target mesangial antigens and initiate glomerulonephritis," Nephron Experimental Nephrology, vol. 121, no. 1-2, pp. e1-e9, 2012.

[13] H. H. Radeke, T. Tschernig, A. Karulin et al., "CD4+ T cells recognizing specific antigen deposited in glomeruli cause glomerulonephritis-like kidney injury," Clinical Immunology, vol. 104, no. 2, pp. 161-173, 2002.
[14] K. MacKay, L. J. Striker, S. Elliot, C. A. Pinkert, R. L. Brinster, and G. E. Striker, "Glomerular epithelial, mesangial, and endothelial cell lines from transgenic mice," Kidney International, vol. 33, no. 3, pp. 677-684, 1988.

[15] E. A. Butz and M. J. Bevan, "Differential presentation of the same MHC class I epitopes by fibroblasts and dendritic cells," Journal of Immunology, vol. 160, no. 5, pp. 2139-2144, 1998.

[16] J. D. Walker, C. L. Maier, and J. S. Pober, "Cytomegalovirusinfected human endothelial cells can stimulate allogeneic CD4+ memory T cells by releasing antigenic exosomes," Journal of Immunology, vol. 182, no. 3, pp. 1548-1559, 2009.

[17] D. F. Lobach, D. P. Bolognesi, and R. E. Kaufman, "Basic Science Review: Retroviruses and Human Cancer: Evaluation of T-Lymphocyte Transformation by Human T-Cell Leukemia-Lymphoma Virus," Cancer Investigation, vol. 3, no. 2, pp. 145-160, 1985.

[18] T. Sekiya and A. Yoshimura, "In vitro Th differentiation protocol," in TGF- $\beta$ Signaling, X. H. Feng, P. Xu, and X. Lin, Eds., vol. 1344 of Methods in Molecular Biology, pp. 183-191, Humana Press, New York, NY, 2016.

[19] C. Strisciuglio, E. Miele, F. P. Giugliano et al., "Bifidobacteria enhance antigen sampling and processing by dendritic cells in pediatric inflammatory bowel disease," Inflammatory Bowel Diseases, vol. 21, no. 7, pp. 1491-1498, 2015.

[20] J. Chandra, Y. Miao, N. Romoff, and I. H. Frazer, "Epithelium expressing the E7 oncoprotein of HPV16 attracts immunemodulatory dendritic cells to the skin and suppresses their antigen-processing capacity," PLoS One, vol. 11, no. 3, article e0152886, 2016.

[21] Y. Yu, A. Arora, W. Min, C. M. Roifman, and E. Grunebaum, "EdU incorporation is an alternative non-radioactive assay to $[(3) \mathrm{H}]$ thymidine uptake for in vitro measurement of mice T-cell proliferations," Journal of Immunological Methods, vol. 350, no. 1-2, pp. 29-35, 2009.

[22] A. Migliorini, R. Ebid, C. R. Scherbaum, and H. J. Anders, "The danger control concept in kidney disease: mesangial cells," Journal of Nephrology, vol. 26, no. 3, pp. 437-449, 2013.

[23] J. R. Sedor, M. Konieczkowski, S. Huang et al., "Cytokines, mesangial cell activation and glomerular injury," Kidney International Supplement, vol. 39, pp. S65-S70, 1993.

[24] P. A. Carpentier, W. S. Begolka, J. K. Olson, A. Elhofy, W. J. Karpus, and S. D. Miller, "Differential activation of astrocytes by innate and adaptive immune stimuli," Glia, vol. 49, no. 3, pp. 360-374, 2005.

[25] C. Mehrfeld, S. Zenner, M. Kornek, and V. Lukacs-Kornek, "The contribution of non-professional antigen-presenting cells to immunity and tolerance in the liver," Frontiers in Immunology, vol. 9, p. 635, 2018.

[26] N. J. Hawkins, R. L. Ward, and D. Wakefield, "Cytokine-mediated induction of HLA antigen expression on human glomerular mesangial cells," Cellular Immunology, vol. 155, no. 2, pp. 493-500, 1994.

[27] M. Giroux, M. Schmidt, and A. Descoteaux, "IFN-gammainduced MHC class II expression: transactivation of class II transactivator promoter IV by IFN regulatory factor-1 is regulated by protein kinase C-alpha," Journal of Immunology, vol. 171, no. 8, pp. 4187-4194, 2003.

[28] A. A. Mostafa, D. Codner, K. Hirasawa et al., "Activation of ER $\alpha$ Signaling Differentially Modulates IFN- $\gamma$ Induced HLAClass II Expression in Breast Cancer Cells," PLoS ONE, vol. 9, no. 1, article e87377, 2014. 
[29] M. Zhao, F. L. Flynt, M. Hong et al., "MHC class II transactivator (CIITA) expression is upregulated in multiple myeloma cells by IFN-gamma," Molecular Immunology, vol. 44, no. 11, pp. 2923-2932, 2007.

[30] L. N. Velasquez, M. A. Milillo, M. V. Delpino et al., "Brucella abortus down-regulates MHC class II by the IL-6-dependent inhibition of CIITA through the downmodulation of IFN regulatory factor-1 (IRF-1)," Journal of Leukocyte Biology, vol. 101, no. 3, pp. 759-773, 2017.

[31] M. Sakatsume, K. Igarashi, K. D. Winestock, G. Garotta, A. C. Larner, and D. S. Finbloom, "The Jak kinases differentially associate with the alpha and beta (accessory factor) chains of the interferon gamma receptor to form a functional receptor unit capable of activating STAT transcription factors," The Journal of Biological Chemistry, vol. 270, no. 29, pp. 1752817534, 1995.

[32] R. B. Munk, K. Sugiyama, P. Ghosh et al., "Antigen-Independent IFN- $\gamma$ Production by Human Naïve CD4+ T Cells Activated by IL-12 Plus IL-18," PLoS ONE, vol. 6, no. 5, article e18553, 2011.

[33] N. Labrecque, L. S. Whitfield, R. Obst, C. Waltzinger, C. Benoist, and D. Mathis, "How much TCR does a T cell need?," Immunity, vol. 15, no. 1, pp. 71-82, 2001.

[34] S. R. M. Clarke and A. Y. Rudensky, "Survival and homeostatic proliferation of naive peripheral CD4+ T cells in the absence of self peptide: MHC complexes," Journal of Immunology, vol. 165, no. 5, pp. 2458-2464, 2000.

[35] I. Grandjean, L. Duban, E. A. Bonney et al., "Are major histocompatibility complex molecules involved in the survival of naive CD4+ T cells?," The Journal of Experimental Medicine, vol. 198, no. 7, pp. 1089-1102, 2003.

[36] F. Winau, G. Hegasy, R. Weiskirchen et al., "Ito cells are liver-resident antigen-presenting cells for activating $\mathrm{T}$ cell responses," Immunity, vol. 26, no. 1, pp. 117-129, 2007.

[37] Y. Waeckerle-Men, A. Starke, P. R. Wahl, and R. P. Wüthrich, "Limited costimulatory molecule expression on renal tubular epithelial cells impairs T cell activation," Kidney \& Blood Pressure Research, vol. 30, no. 6, pp. 421-429, 2007.

[38] A. Goldwich, M. Burkard, M. Olke et al., "Podocytes are nonhematopoietic professional antigen-presenting cells," Journal of the American Society of Nephrology, vol. 24, no. 6, pp. 906-916, 2013.

[39] B. L. Dickinson, "Unraveling the immunopathogenesis of glomerular disease," Clinical Immunology, vol. 169, pp. 8997, 2016.

[40] H. J. Anders and D. A. Muruve, "The inflammasomes in kidney disease," Journal of the American Society of Nephrology, vol. 22, no. 6, pp. 1007-1018, 2011.

[41] S. Hunemorder, J. Treder, S. Ahrens et al., "TH1 and TH17 cells promote crescent formation in experimental autoimmune glomerulonephritis," The Journal of Pathology, vol. 237, no. 1, pp. 62-71, 2015.

[42] L. Gan, Q. Zhou, X. Li et al., "Intrinsic renal cells induce lymphocytosis of Th22 cells from IgA nephropathy patients through B7-CTLA-4 and CCL-CCR pathways," Molecular and Cellular Biochemistry, vol. 441, no. 1-2, pp. 191-199, 2018.

[43] G. Lu, X. Zhang, L. Shen et al., "CCL20 secreted from IgA1stimulated human mesangial cells recruits inflammatory Th17 cells in IgA nephropathy," PLoS One, vol. 12, no. 5, article e0178352, 2017.
[44] T. Masuda, K. Maeda, W. Sato et al., "Growth factor midkine promotes T-cell activation through nuclear factor of activated T cells signaling and Th1 cell differentiation in lupus nephritis," The American Journal of Pathology, vol. 187, no. 4, pp. 740-751, 2017.

[45] H. Suzuki, Y. Suzuki, M. Aizawa et al., "Th1 polarization in murine IgA nephropathy directed by bone marrow-derived cells," Kidney International, vol. 72, no. 3, pp. 319-327, 2007.

[46] Y. Ikezumi, H. Kawachi, S. Toyabe, M. Uchiyama, and F. Shimizu, "An anti-CD5 monoclonal antibody ameliorates proteinuria and glomerular lesions in rat mesangioproliferative glomerulonephritis," Kidney International, vol. 58, no. 1, pp. 100-114, 2000.

[47] X. Feng, J. Hao, Q. Liu et al., "HMGB1 mediates IFN- $\gamma$ induced cell proliferation in MMC cells through regulation of cyclin D1/CDK4/p16 pathway," Journal of Cellular Biochemistry, vol. 113, no. 6, pp. 2009-2019, 2012.

[48] Y. Iwata, K. Furuichi, S. Hashimoto et al., "Pro-inflammatory/Th1 gene expression shift in high glucose stimulated mesangial cells and tubular epithelial cells," Biochemical and Biophysical Research Communications, vol. 443, no. 3, pp. 969-974, 2014.

[49] Y. Cheng, J. Zhang, W. Hou et al., "Immunoregulatory effects of sinomenine on the T-bet/GATA-3 ratio and Th1/Th2 cytokine balance in the treatment of mesangial proliferative nephritis," International Immunopharmacology, vol. 9, no. 78, pp. 894-899, 2009.

[50] C. S. Lim, S. Zheng, Y. S. Kim et al., “Th1/Th2 predominance and proinflammatory cytokines determine the clinicopathological severity of IgA nephropathy," Nephrology Dialysis Transplantation, vol. 16, no. 2, pp. 269-275, 2001.

[51] D. N. Clark, J. L. Markham, C. S. Sloan, and B. D. Poole, "Cytokine inhibition as a strategy for treating systemic lupus erythematosus," Clinical Immunology, vol. 148, no. 3, pp. 335-343, 2013. 


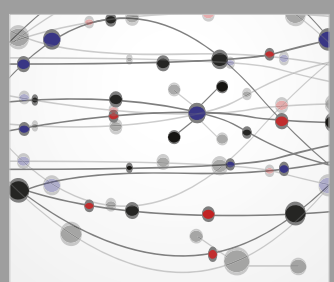

The Scientific World Journal
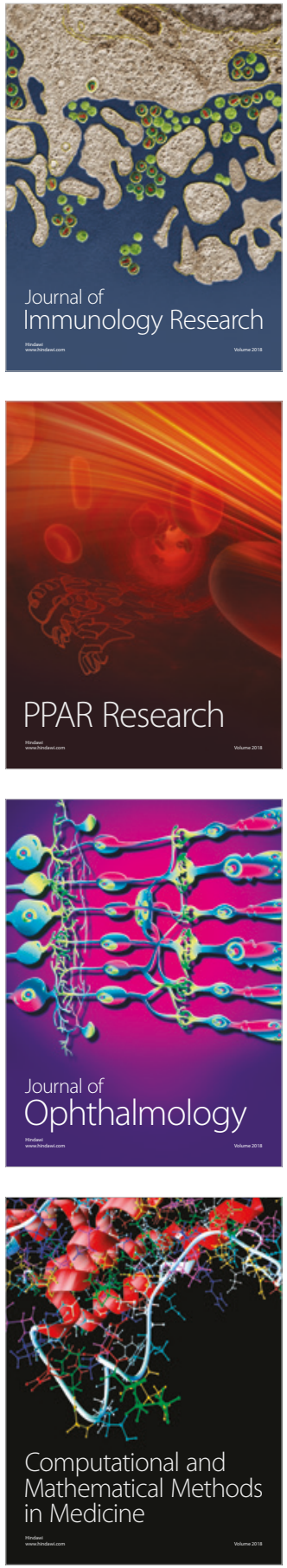

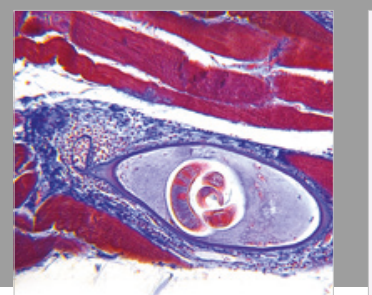

Gastroenterology Research and Practice

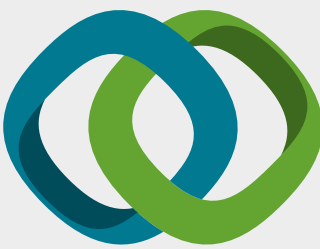

\section{Hindawi}

Submit your manuscripts at

www.hindawi.com
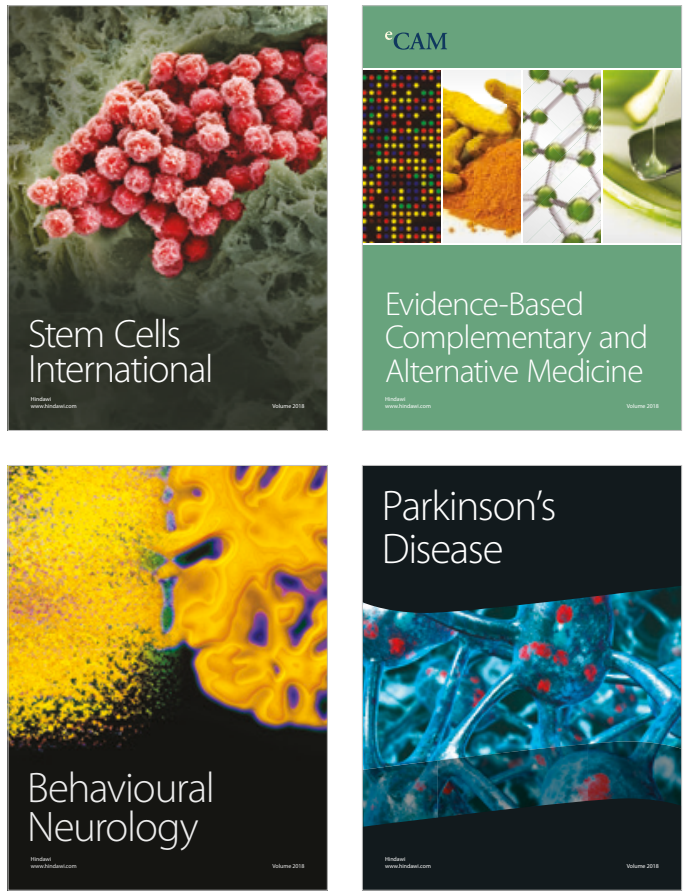

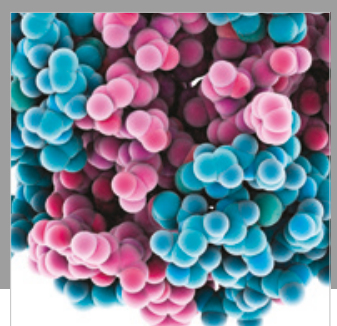

ournal of

Diabetes Research

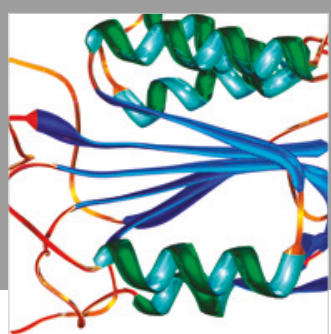

Disease Markers
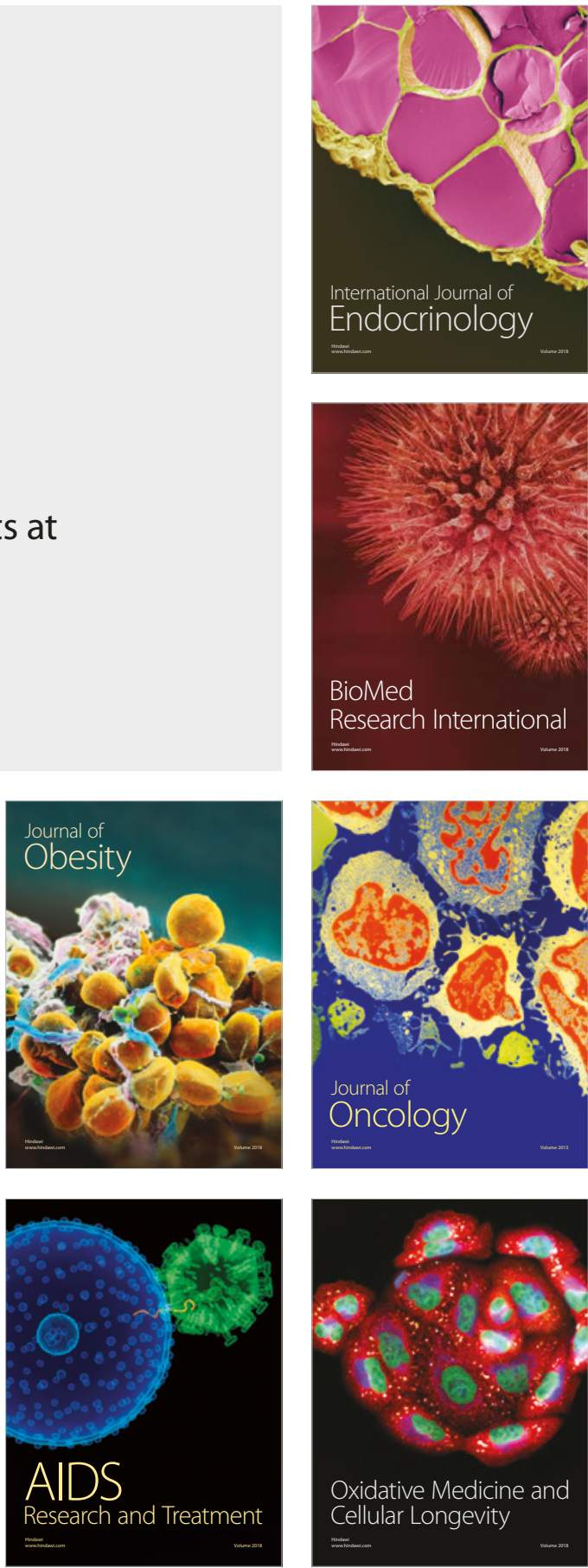